REVESCO. Revista de Estudios Cooperativos

ISSN: $1885-8031$

\title{
Entidades del tercer sector e innovación social. Elementos caracterizadores y factores de éxito
}

\author{
Víctor García-Flores ${ }^{1}$ y Luis Palma $\operatorname{Martos}^{2}(\mathbb{D}$
}

Recibido: 6 de febrero de 2020 / Aceptado: 18 de julio de 2020 / Publicado: 4 de diciembre de 2020

Resumen. La innovación social es un fenómeno que ha sido ampliamente estudiado en la última década debido al auspicio propiciado tanto desde la esfera pública como privada. Sin embargo, hay un vacío en la literatura existente acerca de qué características son definitorias y relevantes para considerar una iniciativa como socialmente innovadora, así como sobre qué papel juegan las entidades del tercer sector en el desarrollo de la innovación social.

Este trabajo tiene dos objetivos principales: en primer lugar, enunciar y ponderar las propiedades más importantes que debe tener una iniciativa para ser considerada innovación social, y, en segundo lugar, basándonos en dichas características, explicar por qué las entidades del tercer sector pueden ser, por su propia naturaleza, sujetos con facilidades para su desarrollo. Con este fin se ha diseñado una metodología cualitativa basada principalmente en la revisión de la literatura, la realización de entrevistas semiestructuradas y el análisis de un caso. Las entrevistas, una vez transcritas, fueron analizadas con el programa Atlas.ti, lo que ha posibilitado identificar y ponderar un total de 18 atributos definitorios de la innovación social que han sido agrupados en 3 grandes bloques. Posteriormente, hemos analizado un proyecto de una entidad del tercer sector y hemos podido observar que todas las características previamente identificadas como definitorias de la innovación social están presentes en éste.

Nuestro trabajo contribuye a crear una mayor evidencia empírica sobre qué aspectos principales deben ser tenidos en cuenta cuando se analiza si un proyecto es socialmente innovador o no. Asimismo, también se aporta un conocimiento relevante acerca de las potencialidades de las entidades del tercer sector como un agente con facilidades para el desarrollo de las innovaciones sociales.

Palabras clave: Economía social; Economía solidaria; Análisis cualitativo; Sociedad civil; Innovación; Organizaciones sociales.

Claves Econlit: B55; L31; 030; 035.

\section{[en] Third sector entities and social innovation. Main features and success-factors}

Abstract. Social innovation is a phenomenon that has been widely studied in the last decade due to the sponsorship from the public and private sectors. However, there is a gap in the existing literature regarding which characteristics define, and are relevant, to consider an initiative as socially innovative. In addition, little work has explored the role third sector organisations play in the development of social innovation.

This work has two main objectives: first, to state and weigh the most important characteristics that an initiative must gather to be considered social innovation, and, second, based on these characteristics, to explain why third sector organisations can be, by their very nature, ideal agents for their development. To this end, a qualitative methodology has been designed based on literature review, semi-structured interviews and case analysis. The interviews, once transcribed, were analyzed with the Atlas.ti program. This has allowed us to identify and measure a total of 18 defining attributes of social innovation, which are then further grouped into 3 thematic groups. Subsequently, we analyzed a project developed by a third sector entity and observe that all the characteristics previously identified as defining social innovation are present.

Our work contributes to creating more empirical evidence on what main aspects should be taken into account when analyzing whether a project is socially innovative or not. Likewise, relevant knowledge is also provided about the potential of third sector organisations as socially innovative agents.

Keywords: Third sector; Social economy; Qualitative analysis; Civil society; Innovation; Social organisations.

Sumario. 1. Introducción. 2. Revisión de la literatura. 3. Notas metodológicas. 4. Discusión de los resultados 5. Las entidades del tercer sector como sujeto ideal para el desarrollo de las innovaciones sociales. Análisis de un caso. 6. Conclusiones. 7. Referencias bibliográficas y Anexos.

Cómo citar. García-Flores, V.; Palma Martos, L. (2020) Entidades del tercer sector e innovación social. Elementos caracterizadores y factores de éxito. REVESCO. Revista de Estudios Cooperativos, vol. 136, e71861. https://dx.doi.org/10.5209/reve.71861.

1 Universidad de Sevilla, España.

Dirección de correo electrónico: victorgarciaflores93@gmail.com.

2 Universidad de Sevilla, España.

Dirección de correo electrónico: 1palma@us.es. 


\section{Introducción}

Los nuevos retos sociales y la grave situación que se produjo tras la última crisis económica han provocado que la innovación social se haya posicionado como un fenómeno en auge debido a sus grandes potencialidades para solucionar problemas y necesidades sociales (Comisión Europea, 2013). Hay que destacar, que dicha situación adversa ha afectado de forma significativa a las entidades del tercer sector, que, con unos recursos escasos, han tenido que hacer frente a unas necesidades crecientes (Fundación Luis Vives, 2012; Fantova, 2015; Sajardo-Moreno y Pérez Sempere, 2019). Esto ha ocasionado que las prácticas socialmente innovadoras, en la medida que permitían mejorar la eficiencia del uso de los recursos disponibles, hayan ido ganando un gran peso en las actividades realizadas por este tipo de entidades (Sajardo-Moreno, 2016).

Sin embargo, debe ser señalado que, aunque la innovación social es un fenómeno histórico, éste no ha comenzado a recibir apoyo institucional hasta estos últimos años (Moulaert y McCallum, 2019). De hecho, este auge del concepto viene originado por la institucionalización realizada por organismos como la Comisión Europea, que, en 2010, reconocía sus potencialidades a partir de iniciativas como Unión por la Innovación y Plataforma Europea contra la Pobreza y la Exclusión Social. Posteriormente, con la publicación en 2013 del Social Innovation Package y la Guide to Social Innovation, la consolidación del concepto se convirtió en una realidad. Desde ese momento, se han diseñado y puesto en marcha multitud de planes y estrategias a diferentes niveles institucionales con un objetivo común: favorecer la innovación social.

Este creciente número de programas dedicados a apoyar técnica y financieramente a la innovación social, junto a la mencionada escasez de recursos existente, ha provocado que haya un número cada vez mayor de entidades que tratan de autodenominarse como socialmente innovadoras para poder optar a esas nuevas vías de financiación. Esto ha causado que exista un interés gradual en conocer qué es una iniciativa socialmente innovadora y qué características tiene ésta.

Actualmente, hay una amplia amalgama de definiciones reconocidas y que tratan el fenómeno desde diferentes perspectivas, lo que dificulta encuadrar el término en unas características definitorias propias (Hernández-Ascanio et al., 2016; Palma et al., 2017; Salom-Carrasco et al., 2017; García-Flores y Palma, 2019). Este hecho ha desencadenado en que, a menudo, se reconozcan y financien prácticas que no cumplen con los principales principios y propiedades de la innovación social. Son muchas las entidades que a partir de la inclusión de prácticas de responsabilidad social o de emprendimiento social han pretendido encuadrarse bajo el marco de la innovación social.

Por lo tanto, nosotros partimos de la hipótesis de que, si queremos mejorar la toma de decisiones y los criterios de selección para el apoyo de las iniciativas, es primordial conocer qué características deben tener para ser consideradas como socialmente innovadoras. Por esta razón, y desde el convencimiento de que las entidades del tercer sector están en perfecta consonancia con los principales atributos de las iniciativas socialmente innovadoras, este trabajo tiene dos fines principales: el primero es explicar qué características tiene una innovación social y, el segundo, mostrar cómo las entidades del tercer sector pueden ser una de las organizaciones con facilidades para desarrollarlas con éxito.

Para alcanzar estas metas se ha planteado una metodología cualitativa a partir de la realización de una revisión sistemática de la literatura, una serie de entrevistas semiestructuradas a un total de 24 agentes conectados con la innovación social y el análisis de un caso. La revisión de la literatura ha permitido conocer la complejidad y problemática del mencionado fenómeno, estableciendo así los primeros nexos e implicaciones entre los conceptos de innovación social y las entidades del tercer sector. Posteriormente, con el análisis de las entrevistas hemos logrado exponer un conjunto de atributos que son propios de la innovación social. Así, finalizamos con el análisis del caso de una práctica reconocida como socialmente innovadora que muestra el encaje existente entre el proyecto de una entidad del tercer sector y los atributos previamente identificados con el análisis de las entrevistas.

Entre las principales contribuciones de este trabajo se encuentran: i) enunciar y explicar las características, algunas ya señaladas en la literatura previamente y otras nuevas, que debe tener cualquier iniciativa para que sea considerada como socialmente innovadora, ii) ponderar estos atributos para conocer la relevancia de cada uno cuando haya que valorar las iniciativas y iii) mostrar qué, efectivamente, en el tercer sector existen entidades que han desarrollado iniciativas cuyas características están en total afinidad con los principios de la innovación social.

Este trabajo se estructura de la siguiente forma. Un segundo epígrafe, posterior a esta introducción, en el que, mediante una revisión de la literatura se precisan los conceptos de entidad del tercer sector e innovación social, y se relacionan ambos; un tercer epígrafe en el que se presenta la metodología usada para la elaboración del presente artículo; un cuarto epígrafe en el que se discuten los resultados obtenidos tras el análisis de las entrevistas; un quinto epígrafe en el que se realiza el análisis de caso y, por último, se finaliza exponiendo las principales conclusiones y la bibliografía utilizada para la realización de este trabajo. 


\section{Revisión de la literatura}

\subsection{Las entidades del tercer sector}

El término tercer sector fue acuñado originalmente a principios del siglo XX en Estado Unidos. Surge en un contexto donde se comenzaban a consolidar políticas conservadoras acerca de la potestad del sector público en materias sociales (Salamon y Anheier, 1996; Roitter, 2004). No obstante, el concepto no tomó verdadera importancia hasta los años ochenta, coincidiendo con el gobierno de Ronald Reagan. Su consolidación llegaría en los años noventa, cuando fue exportado a Europa Occidental.

Las entidades del tercer sector, según el informe Radiografía del Tercer Sector Social en España: retos y oportunidades en un entorno cambiante, elaborado por $\mathrm{PwC}$ (2018: 8), pueden ser definidas como "entidades privadas, formalmente organizadas, de carácter voluntario y sin ánimo de lucro cuyo propósito principal es impulsar el reconocimiento y ejercicio efectivo de los derechos sociales para avanzar hacia una sociedad más cohesionada e inclusiva, incluyendo dentro de las mismas a las entidades de cooperación internacional y de medio ambiente". Este tipo de entidades se han caracterizado históricamente por prestar, de forma complementaria o alternativa, servicios sociales. De hecho, en el informe de PwC (2018) se plantea su papel subsidiario en la prestación de servicios allí donde ni la acción del sector público ni el mercado lo hacen.

Sin embargo, apunta Roitter (2004) que las entidades del tercer sector no son ajenas al mercado, ya que existe una fuerte relación entre éstas, el sector público y el sector privado capitalista. En este sentido, y dentro de la lógica de la economía de mercado, el entonces Comisario de Mercado Interior, Michel Barnier, durante la conferencia "Social Economy and Social Business" celebrada en Bruselas en noviembre de 2011, afirmó que "las entidades del tercer sector representan justo el modelo de crecimiento sostenible, integrador $e$ inteligente, basado en la innovación, que tanta relevancia tiene para la economía europea". Para Michel Barnier este tipo de entidades son un salvoconducto para conseguir, dentro del sistema económico actual, unos resultados más sociales e inclusivos.

En esta línea, Salamon y Anheier (1994) aseveraron que precisamente las entidades del tercer sector destacaban por ayudar a conseguir un mayor desarrollo económico. Por su parte, Torres (2010) señala que a partir del fomento de nuevas formas de acción y participación de la sociedad civil se posibilitaba una mayor contribución al bienestar social. Así, las entidades del tercer sector pueden coadyuvar a reactivar el tejido social y mejorar la canalización de las necesidades sociales y organizativas de la sociedad civil.

Por otro lado, la estructura financiera de las entidades del sector se caracteriza por estar compuesta por recursos económicos de las donaciones de particulares y empresas, de las subvenciones y ayudas procedentes del sector público, de los beneficios obtenidos de las actividades mercantiles que realizan y de las cuotas de sus asociados (Torres, 2010; Rincón, 2013). No obstante, la principal fuente de financiación ha sido tradicionalmente el sector público (Roitter, 2004; Torres, 2010). A este respecto, afirma Sajardo-Moreno (2016) que este hecho ha ocasionado muchos problemas en la estructura financiera de las entidades, especialmente en las de aquellas que tenían menor tamaño. La mencionada dependencia financiera se vio aún más agravada con el inicio de la última crisis económica provocada por la reducción tanto de financiación pública como privada. Esto ocasionó serias dificultades en las entidades para poder seguir llevando a cabo sus acciones (Fresno y Rauchberger, 2015; PwC, 2018).

Es importante también apuntar que las entidades del tercer sector pertenecerían según Rincón (2013:148) "al subsector de no mercado, conformado en su mayoría por asociaciones y fundaciones que ofrecen servicios, que pueden comercializar en los mercados, pero siempre a precios económicamente no significativos". En este sentido, este tipo de entidades tienen su razón de ser por iniciativa y voluntad propia para llevar a cabo actividades y prestar servicios de beneficio social a favor de determinados colectivos que demandan dichos servicios (Rincón, 2013; López-Cózar et al., 2015). El propio Rincón (2013) enuncia que entre las principales iniciativas se encuentra la realización de actividades caracterizadas "por la cooperación, la ayuda mutua, la solidaridad, la autogestión de los beneficios de sus asociados, de su familia, de las personas relacionadas con estos y de la comunidad en general".

Todas estas características y valores propios de las entidades del tercer sector han originado que numerosos autores hayan puesto su atención en sus potencialidades para desarrollar la innovación social. Anheier (2014), Buckland y Murillo (2014) y Fantova (2015) plantean en sus respectivos trabajos las potencialidades de estas organizaciones para realizar proyectos socialmente innovadores. Por ello, creemos que es fundamental antes de pasar a analizar el estado del arte sobre la relación entre innovación social y entidades del tercer sector, conocer la problemática existente sobre las características de la innovación social.

\subsection{Características de la innovación social}

La compresión de las actividades de innovación y sus características ha sido objeto de estudio de numerosas investigaciones a lo largo de las últimas décadas. Moulaert y McCullam (2019: 12) afirman que "en 
contraste con el significado predominante de innovación en el mundo contemporáneo -muy relacionado con la tecnología-, históricamente era una idea altamente relacionada con el cambio social derivado de la acción colectiva y el conflicto socio político". Estos autores llegan a señalar que "la innovación era más o menos un sinónimo de una forma radical de innovación social, predominantemente conectada con la transformación social a través de la revolución o la desatención al orden natural del poder político".

Sin embargo, desde que Schumpeter (1942:120) hizo referencia a ésta como "el proceso de mutación industrial que revoluciona incesantemente la estructura económica desde dentro, destruyendo ininterrumpidamente lo antiguo y creando continuamente elementos nuevos" irrumpió un novedoso paradigma en el que los aspectos sociales de la innovación han sido sistemáticamente olvidados. Schumpeter (1942:121) entendía que "el impulso fundamental que pone y mantiene en movimiento la máquina capitalista procede de los nuevos bienes de consumo, de los nuevos métodos de producción y transporte, de los nuevos mercados y de las nuevas formas de organización industrial que crea la empresa capitalista". En esta idea, prevalece la relevancia de la figura del empresario innovador como el sujeto clave en el proceso de destrucción creadora, lo que ha provocado que, durante muchos años, haya predominado la idea de que la sociedad era sólo el ámbito donde se desarrollaban las innovaciones, relegándola a un papel contextual y no contemplando la posibilidad de que ésta se erigiera en un agente innovador.

Sin perjuicio de lo anterior, las innovaciones sociales se han ido desarrollando a lo largo de la historia cuando se han pretendido resolver retos sociales, independientemente del paradigma predominante en ese momento (López y González, 2013). De hecho, Zubero (2015: 14) subraya que "la innovación social es tan característica de las sociedades humanas vivas que sería un error reducirla a una práctica exclusiva de las denominadas sociedades modernas".

En esta línea, apuntan Echeverría y Merino (2011) que el cambio de paradigma y el giro social en los estudios de innovación no se comienza a producir hasta finales del siglo XX. En este periodo se comienza a defender la innovación social como alternativa y complemento a la innovación tecnológica en países como Australia, Nueva Zelanda, Canadá y Gran Bretaña. El paradigma tradicional va modificándose hacia un nuevo enfoque en el que la sociedad se posiciona como un agente innovador y el conocimiento y la información son la base de la transformación.

En los últimos tiempos han sido muchos los autores que han realizado investigaciones sobre innovación social desde diferentes prismas y enfoques (Mulgan, 2006; Djellal y Gallouj, 2012; Zubero, 2015; Hernández-Ascanio et al., 2016; Palma et al., 2017; Salom-Carrasco et al., 2017). Por ello, la consecución de una definición generalmente reconocida se ha convertido en una de las grandes cuestiones a abordar en este campo. En García-Flores y Palma (2019: 262) se considera innovación social "aquellas prácticas o iniciativas llevadas a cabo por la comunidad que, a partir de los productos, servicios o modelos que generan, o bien a través del proceso diseñado para conseguir sus objetivos, alcanzan soluciones que dan una mejor respuesta, de forma alternativa y creativa, a problemas o necesidades sociales".

En este sentido, lo cierto es que la inexistencia de un conjunto de propiedades canónicas, estándares y únicas que una iniciativa socialmente innovadora debe de tener para ser reconocida como tal, es una carencia teórica importante. Esto deriva en el uso inapropiado que, de forma en muchos casos partidista, se hace del concepto. Con el objeto de mostrar esa diversidad y la falta de consenso existente sobre qué características son propias de la innovación social se ha elaborado la tabla 1. 
Tabla. 1. Características de la innovación social

\begin{tabular}{|l|l|}
\hline Característica principal & Autores \\
\hline Procesos de creación colectiva & Phills et al. (2008) \\
\hline Invierten las relaciones de poder & $\begin{array}{l}\text { Lawson y Lorenz (1999); Mulgan (2006); Hubert (2010); } \\
\text { Moulaert et al. (2013) }\end{array}$ \\
\hline $\begin{array}{l}\text { Procesos que incrementan la } \\
\text { eficiencia y la eficacia }\end{array}$ & $\begin{array}{l}\text { Caulier-Grice et al. (2012); } \text {; Oosterlynck et al. (2013); } \\
\text { Cajaiba-Santana (2014) }\end{array}$ \\
\hline $\begin{array}{l}\text { Incrementan la sostenibilidad } \\
\text { global }\end{array}$ & Avelino y Wittmayer (2016); World Economic Forum (2016) \\
\hline Generadora de equidad & Godin (2012) \\
\hline Solidaridad & Moulaert y Nussbaumer, (2005) \\
\hline Fenómeno urbano y local & $\begin{array}{l}\text { Subirats (2015); Rodríguez-García y Mateos (2015); García- } \\
\text { Flores y Palma (2019) }\end{array}$ \\
\hline Generador de inclusión social & Navarro (2015); Blanco et al. (2016) \\
\hline Potenciador de alianzas & Hubert (2010) \\
\hline Replicables ${ }^{4}$ y escalables & Subirats (2015) \\
\hline Sustituto de servicios públicos & BEPA (2014) \\
\hline $\begin{array}{l}\text { Implica al sector público, al sector } \\
\text { privado y a la sociedad civil }\end{array}$ & $\begin{array}{l}\text { Subirats (2015); Rodríuez-García y Mateos (2015); García- } \\
\text { Flores y Palma (2019) }\end{array}$ \\
\hline
\end{tabular}

Fuente: Elaboración propia

La tabla 1 recoge las propiedades definitorias más importantes mencionadas por organismos nacionales e internacionales, así como por autores de referencia en la materia. Como podemos observar cada autor destaca un atributo definitorio diferente de la innovación social. Esta situación viene causada, tal y como señalan García-Flores y Palma (2019), por la coexistencia de diferentes enfoques y formas de entender la innovación social. Esto puede dar origen a que se piense que la innovación social es un concepto paraguas, lo que significa, según Hirsch y Levin (1999: 34), que es "un constructo amplio utilizado para abarcar y explicar una diversidad de fenómenos". Desde nuestro punto de vista, aunque entendemos que la innovación social es un concepto de gran vastedad que trata de encuadrar fenómenos sociales dispares e innovadores, no debe ser aceptado que sea un concepto paraguas.

A este respecto, Zubero (2015) afirma que el polimorfismo o la indefinición de la innovación social está muy relacionado con el hecho de que se haya constituido como un campo liderado por individuos y grupos fundamentalmente preocupados por la práctica (practice-led field) y mucho menos por la reflexión académica (Caulier-Grice et al., 2012). Por ello, entendemos que para definir un conjunto de características y propiedades de la innovación social es necesario hacer una reflexión teórica teniendo en cuenta la visión de los individuos y los grupos que han realizado iniciativas socialmente innovadoras. Sólo de este modo es posible conocer la realidad con pragmatismo.

Por último, una vez presentadas las principales características que se plantean en la literatura como definitorias de la innovación social, vamos a pasar a mostrar algunas de las premisas más relevantes que relacionan la innovación social con las entidades del tercer sector.

\subsection{Entidades del tercer sector e innovación social}

Señalan Moulaert y McCallum (2019) que históricamente el término innovación social ha sido usado para las acciones de movimientos sociales como los surgidos en el siglo XIX que defendían los derechos laborales o el sufragio universal. Aun en la actualidad, las organizaciones más relevantes en el ámbito de la innovacion social, como la Young Foundation o la National Endowment for Science Technology and Arts (NESTA), argumentan que las prácticas socialmente innovadoras surgen de manera embrionaria desde la sociedad civil.

Lo cierto es que existen muchos agentes económicos y sociales que participan e incluso lideran proyectos socialmente innovadores que no son entidades del tercer sector. En este sentido, Murray et al. (2010) y Borzaga y Bodini (2012) plantean que los sujetos que pueden llevar a cabo iniciativas socialmente innovadoras son bastante diversos, pudiendo éstas ser desarrolladas por la propia acción pública, por el

3 La definición es realizada en el proyecto europeo TEPSI (The theoretical, empirical and policy foundations for building social innovation in Europe), en el que participa como socio la Young Foundation.

4 La escalabilidad se refiere al hecho de que una iniciativa desarrollada en un entorno local pueda pasar a llevarse a cabo en ámbitos territoriales de mayor tamaño (Subirats, 2015)

La replicabilidad hace referencia a la posibilidad de mimetizar una iniciativa en un territorio o ámbito similar (Buckland y Murillo, 2014). 
sector privado capitalista e incluso por organizaciones híbridas. En contraposición a los argumentos de estos autores, existe una extensa literatura que, aunque no niega la existencia de que la innovación social pueda ser desarrollada por diferentes tipos de entidades o empresas, defiende la hipótesis de que las entidades del tercer sector son las mejor posicionadas para desarrollar las innovaciones sociales (Buckland y Murillo, 2014; Díaz-Foncea y Marcuello, 2014; Anheier, 2014; Fantova, 2015).

No obstante, debemos ser cautelosos cuando analizamos las acciones e iniciativas de las entidades del tercer sector, ya que, además de acciones socialmente innovadoras estas entidades realizan otro tipo de iniciativas con lógicas más tradicionales. Fazzi (2014) señala que, aunque las entidades del tercer sector pueden postularse como los agentes principales para el nacimiento y la consolidación de iniciativas socialmente innovadoras, no todas las prácticas o acciones que sean desarrolladas por éstas deben ser consideradas como tal per se.

Sin embargo, y aunque es completamente cierto que no todas las iniciativas que realizan las entidades del tercer sector son innovaciones sociales, son cada vez más las que ponen en marcha proyectos socialmente innovadores. El motivo principal de ello, aparte de la posibilidad de poder obtener nuevas vías de financiación como ya hemos comentado anteriormente, es que el desarrollo de la innovación social por parte de las entidades del tercer sector supone una ventaja competitiva para ellas en cuanto al posicionamiento que deben tomar en la nueva sociedad del conocimiento y la información (Fantova, 2015). La innovación social supone incorporar al funcionamiento de las entidades del tercer sector novedosas herramientas y metodologías vinculadas a la innovación social como el fomento de la cultura colaborativa, el design thinking ${ }^{6}$ o el speed meeting ${ }^{7}$.

En cualquier caso, independientemente de la necesidad de aumentar la eficiencia de sus procesos, las entidades del tercer sector, por su contacto permanente con la sociedad civil, ocupan un lugar privilegiado en el desarrollo de las innovaciones sociales por su capacidad para identificar necesidades sociales nuevas o insatisfechas (Social Platform; 2013).

De esta forma, señala Bason (2010) que la colaboración de la administración pública con las entidades del tercer sector que llevan a cabo innovaciones sociales genera unos efectos positivos mayores a los de otros tipos de colaboraciones -como las realizadas por el sector público y el sector privado capitalista-. Esto sucede porque las entidades del tercer sector anteponen los valores y la misión social que dan motivación a su razón de ser, a la maximización de beneficios. Además, tal y como subrayan Ariño y Atxutegi (2017), este tipo de entidades destacan por otras características particulares, así como por su capacidad de definir e implementar estrategias colectivas.

Por todo ello, creemos que es necesario seguir avanzando en el estudio de la relación existente entre las entidades del tercer sector y la innovación social. Con el fin de profundizar en el análisis entendemos que es primordial crear un nuevo marco teórico de referencia acerca de las características principales que debe tener una iniciativa para ser reconocida como tal. Sólo así conseguiremos paliar una de las mayores limitaciones existentes en la literatura actual.

\section{Notas metodológicas}

Para el desarrollo de este trabajo se han utilizado una serie de técnicas de análisis básicamente cualitativas. Concretamente, se ha diseñado una metodología que combina: la revisión de la literatura y la realización de entrevistas semiestructuradas, con el análisis de un caso.

Con respecto a la revisión de la literatura se ha llevado a cabo un estudio exhaustivo de los trabajos académicos más citados, así como de los principales informes publicados por instituciones locales, nacionales e internacionales. Esto ha permitido conocer los diferentes prismas desde los que se puede entender la innovación social, las particularidades que pueden tener las entidades del tercer sector y las potencialidades de éstas para desarrollar prácticas socialmente innovadoras. Una vez realizada la revisión de la literatura, y siendo conocedores de la problemática y dificultades existentes, se hicieron las entrevistas semiestructuradas para, teniendo en cuenta la literatura, analizar el discurso y estudiar las particularidades y las características propias de la innovación social.

Por último, una vez conocidas las características que una práctica socialmente innovadora debe tener para que sea considerada como tal, se pasa a analizar un caso de un proyecto de una entidad del tercer sector. Con ello mostramos el encaje que existe entre un proyecto liderado y desarrollado por una asociación sin ánimo de lucro y las características propias y definitorias de la innovación social.

6 El design thinking es una herramienta enfocada en fomentar la innovación en las organizaciones a partir de una metodología participativa, en la que el diseño y el proceso tienen mayor peso que el producto final.

El speed meeting hace referencia a evento de networking, que, bajo un formato lúdico, ayudan a crear contactos profesionales 


\subsection{Entrevistas}

Con el fin de identificar los aspectos claves y comunes que debe tener cualquier iniciativa que sea considerada como socialmente innovadora, los distintos tipos de ésta, así como para conocer el estado del arte y la realidad social, se han realizado un total de 24 entrevistas semiestructuradas ${ }^{8}$.

Las entrevistas han sido organizadas en varias partes: una primera en la que se realizaban preguntas genéricas sobre innovación social; una segunda en la que se cuestionaba acerca de los aspectos más importantes de su proceso de creación y, por último, una sección dedicada a los efectos y resultados que, en opinión de los entrevistados, la innovación social puede generar?.

Los agentes entrevistados se pueden agrupar en tres tipos ${ }^{10}$ : responsables de iniciativas postuladas como socialmente innovadoras, agentes y dinamizadores de la innovación social y científicos que han realizado trabajos de impacto en esta área.

Los entrevistados han sido seleccionados teniendo en consideración:

- $\quad$ La experiencia y la relevancia del proyecto

- La trayectoria académica y profesional

- Los reconocimientos y premios que organismos de prestigio les han otorgado en materia de innovación social a ellos mismos, o a los colectivos que representan.

En total se trató de contactar con 87 personas, siendo 24 las que finalmente realizaron las entrevistas. En la selección de los sujetos también existió un cierto grado de oportunidad que el propio avance de la investigación propició. Los propios entrevistados nos facilitaron en ocasiones la posibilidad de contactar con expertos y perfiles interesantes que cumplían con los criterios establecidos. La realización de las entrevistas tuvo lugar durante los meses de junio, julio septiembre, octubre y noviembre de 2018, de forma presencial o a distancia. Éstas tuvieron una duración media de entre 50 y 75 minutos.

\subsubsection{Tratamiento de los datos de las entrevistas}

El programa informático Atlas.ti ha sido usado con el fin de analizar el contenido de las 24 entrevistas realizadas. Prados (2007: 62) señala que "Atlas.ti es una herramienta informática la cual es capaz de analizar datos cualitativos complejos de forma estructurada (...) que se articula alrededor de la Grounded Theory, y que trata de generar teoría a la vez que investiga en la materia; ambas como parte de un mismo proceso". Esto ha facilitado el trabajo interpretativo y el análisis del contenido. Este análisis permite descubrir componentes básicos de un fenómeno concreto teniendo en consideración las ideas expresadas por los entrevistados a partir de palabras y frases (Noguero, 2002).

En este sentido, Escalante (2009) subraya que las expresiones y los conceptos presentes en un texto son de elevada significatividad, ya que, a partir de ellos, podemos identificar su importancia y relación. Así, con el objetivo de explorar e interpretar los textos hemos analizado los contextos lingüísticos y semánticos de aquellas palabras o frases que eran susceptibles de expresar un concepto.

Lo primero que hemos llevado a cabo tras la transcripción de las entrevistas es su codificación. Este proceso es una forma de reducción de datos, ya que, partiendo de un gran volumen de información, hemos logrado segmentar ciertos fragmentos de la información (citas) y etiquetarlas a partir de códigos (PérezLópez et al., 2015). Estos son los elementos principales de análisis y son considerados como un sistema de categorías. En nuestro caso, cada vez que hemos identificado una cita, que hacía referencia a una característica definitoria de la innovación social, hemos etiquetado un código -referido a un determinado atributo relacionado con el contenido de la cita ${ }^{11}$-. Por consiguiente, la codificación ha contribuido a realizar conexiones entre las diferentes partes de la información que disponemos.

Hay que destacar que el programa Atlas.ti integra la herramienta WordCruncher para contar la frecuencia absoluta de los códigos que hemos etiquetado ${ }^{12}$. Plantea Noguero (2002) que dichas frecuencias de aparición de los códigos son esenciales para realizar un análisis estadístico del contenido.

8 Se ha utilizado esta técnica porque, tal y como señala McCrakent (1991), la entrevista es una de las herramientas más poderosas de la investigación y a partir de ella se pueden conocer y analizar de forma detallada las distintas variables que señalan los expertos entrevistados, buscando el discurso común de todos ellos, y consiguiendo identificar las principales variables y factores que han de ocurrir para que surjan las innovaciones sociales.

- En el anexo 1 puede ser consultado el guión seguido para realizar las entrevistas semiestructuradas.

10 En el anexo 2 pueden ser consultado el perfil de todas las personas entrevistadas durante este estudio.

11 En una cita pueden identificarse uno o más factores, lo que hace que se pueda etiquetar dicha cita con uno o más códigos. Cuando en una cita se etiquetan más de un código, estos coocurren, lo que es signo evidente de que puede existir una relación entre las características a las que representan.

12 Las frecuencias absolutas de los códigos hacen referencia al número de veces que una cita ha sido identificada con un mismo código. Por lo tanto, la frecuencia absoluta nos da información acerca del número de veces que en el contenido del texto transcrito se ha hecho referencia a una característica determinada. 
Posteriormente, una vez calculadas las frecuencias absolutas de los códigos, con el propósito de obtener más información acerca de la relevancia de cada uno de ellos, hemos calculado la frecuencia relativa de esos códigos que eran representativos de características propias de la innovación social ${ }^{13}$.

Una vez identificados los códigos y conocidas sus frecuencias, se generaron redes de coocurrencia ${ }^{14}$ que permitieron analizar las diferentes interacciones entre cada uno de los códigos señalados. Esto ha facilitado la agrupación de las características por afinidad, creando tres grandes bloques que engloban a cada una de ellas.

\subsection{Análisis de casos}

Para este estudio se ha seleccionado un caso de una práctica socialmente innovadora. La iniciativa elegida es relevante y reconocida por diferentes programas de innovación social, como el "Programa de apoyo a la implementación de proyectos de Innovación Social" del Centro de Innovación Social "La Noria" y la obra social "La Caixa".

El análisis de caso se lleva a cabo teniendo en cuenta la definición de innovación social más aceptada por los entrevistados, la de la Comisión Europea (2013: 6):

Es el desarrollo e implementación de nuevas ideas (productos, servicios y modelos) para satisfacer las necesidades sociales, crear nuevas relaciones sociales y ofrecer mejores resultados. Sirve de respuesta a las demandas sociales que afectan al proceso de interacción social, dirigiéndose a mejorar el bienestar humano.

Partiendo de esta definición, son tres los interrogantes a los que queremos responder para presentar el caso:

- ¿Qué nuevo producto/servicio/modelo se propone?

- ¿Qué problema o necesidad social se satisface?

- ¿Cuál es la mejora que se introduce?

Una vez explicado el caso y respondidas las cuestiones planteadas, nosotros proponemos una nueva cuestión ¿es realmente un proyecto socialmente innovador? Con el objetivo de responder a ello, observamos si las características previamente identificadas pueden ser vinculadas al proyecto desarrollado.

Por último, debemos señalar que para el estudio del caso se han utilizado diferentes fuentes información. Concretamente, hemos utilizado documentos públicos que contenían información de interés y documentos que han sido facilitados por el Grupo de Desarrollo Rural Valle del Guadalhorce. También se han realizado dos entrevistas semiestructuradas en diferentes fases temporales a la responsable de la iniciativa. La primera para conocer en profundidad toda la iniciativa y la segunda para observar la evolución de ésta y validar si todo lo recogido en los resultados era correcto.

\section{Discusión de los resultados}

Una vez realizada la revisión de la literatura y explicada la metodología empleada, pasamos a presentar los resultados obtenidos. En la tabla 2 podemos observar cómo las características definitorias de la innovación social pueden ser agrupadas en tres grandes bloques: características de las relaciones de los agentes participantes en el proyecto, características propias del proyecto y efectos característicos de la innovación social. Estos tres bloques están formados por un total de 18 características.

13 La frecuencia relativa hace referencia al número de veces que se repite un código determinado con respecto al número total de veces que se repiten todos los códigos.

14 La coocurrencia hace referencia a aquellos códigos que tienen una relación en el sentido de que coocurren en alguna cita. Ver nota 9. 
Tabla. 2. Identificación de las características de la innovación social por bloques

Bloque A: Características de las relaciones de los agentes con el proyecto

\begin{tabular}{|l|r|r|}
\cline { 2 - 3 } \multicolumn{1}{c|}{} & Frecuencia absoluta & \multicolumn{2}{l|}{ Frecuencia relativa } \\
\hline $\begin{array}{l}\text { 1. Interconexión entre distintos } \\
\text { agentes }\end{array}$ & 30 & 0,11718 \\
\hline 2. Acción social colectiva & 22 & 0,08593 \\
\hline 3 Colaboración & 20 & 0,07812 \\
\hline 4. Participación de los interesados & 18 & 0,07031 \\
\hline 5. Proximidad & 9 & 0,03515 \\
\hline 6. Elaboración de redes & 8 & 0,03125 \\
\hline Totales & 107 & 0,41794 \\
\hline
\end{tabular}

Bloque B: Características propias del proyecto

\begin{tabular}{|l|r|r|}
\cline { 2 - 3 } \multicolumn{1}{c|}{} & Frecuencia absoluta & $\begin{array}{l}\text { Frecuencia } \\
\text { Relativa }\end{array}$ \\
\hline 7. Elemento territorial & 23 & 0,08984 \\
\hline 8. Replicabilidad y escalabilidad & 16 & 0,0625 \\
\hline 9. Presencia de creatividad & 14 & 0,05468 \\
\hline 10. Metodologías inclusivas & 10 & 0,03906 \\
\hline 11. Proceso de aprendizaje & 8 & 0,03125 \\
\hline 12. Cooperación & 7 & 0,02734 \\
\hline 13. Proceso de abajo a arriba & 7 & 0,02734 \\
\hline Totales & 85 & 0,33201 \\
\hline
\end{tabular}

Bloque C: Efectos característicos

\begin{tabular}{|l|r|r|}
\cline { 2 - 3 } \multicolumn{1}{c|}{} & Frecuencia absoluta & \multicolumn{2}{l|}{ Frecuencia relativa } \\
\hline 14. Repercute en la sociedad civil & 19 & 0,07421 \\
\hline 15. Aumenta la calidad de vida & 14 & 0,05468 \\
\hline 16. Transformación política & 14 & 0,05468 \\
\hline 17. Fenómeno transversal & 11 & 0,04296 \\
\hline $\begin{array}{l}\text { 18. Respuestas más eficientes y } \\
\text { eficaces }\end{array}$ & 6 & 0,02343 \\
\hline Totales & 64 & 0,24996 \\
\hline
\end{tabular}

Fuente: Elaboración propia a partir de los datos proporcionados por las entrevistas realizadas y procesadas a través del software Atlas.ti.

En la tabla 2 se muestran las características que definen a una iniciativa socialmente innovadora, los bloques en los que se agrupan y sus respectivas frecuencias absolutas y relativas. Dichas frecuencias son utilizadas como proxy para ponderar la importancia de cada una de las características y los bloques señalados. Esto permite conocer en qué atributos de una iniciativa debe centrarse más la atención cuando se pretende determinar si es socialmente innovadora o no.

Cada uno de los bloques, formados a partir de la agrupación de las características afines, representan las diferentes partes que deben ser tenidas en cuenta para analizar una iniciativa socialmente innovadora. Podemos observar que el primero de los bloques engloba aquellas características relacionadas con el tipo de relaciones que suelen tener los agentes implicados en los proyectos socialmente innovadores, el segundo hace referencia a las características que una vez desarrollado el proyecto lo caracterizan y el tercero recoge los efectos que son definitorios y propios de los procesos socialmente innovadores.

Las cinco características más importantes para determinar si una iniciativa es socialmente innovadora son: la existencia de interconexión entre distintos agentes económicos y sociales (0.1171), el marcado carácter 
territorial (0.0898), la canalización de la acción social colectiva (0.085), la existencia de colaboración (0.078) y que la acción repercuta en la sociedad civil (0.074). De las cinco características mencionadas, tres de ellas se concentran en el primer bloque, lo que sugiere la importancia del proceso por el que se fraguan los proyectos socialmente innovadores.

Por lo tanto, en la tabla 2, se aporta un conocimiento de utilidad para aquellas entidades, tanto públicas como privadas, interesadas en analizar prácticas e iniciativas socialmente innovadoras. La valoración de las iniciativas y la delimitación de lo que es y no innovación social es un asunto complejo y relevante que necesita de información para mejorar la toma de decisiones. Con la ponderación de los criterios, aquellos que tienen que tomar decisiones para otorgar ayudas, subvenciones o establecer estrategias, tienen una guía sobre las propiedades fundamentales sobre las que deben enfocar su atención. A continuación, pasamos a explicar, por bloques y por orden de significatividad relativa, cada uno de sus componentes y sus posibles interrelaciones.

\subsection{Características de las relaciones de los agentes participantes en el proyecto}

Estas características se refieren a aquellas que están más relacionadas con el proceso de creación del proyecto y los agentes que diseñan la iniciativa. Este bloque engloba un total de seis atributos.

La característica más destacada es la existencia de interconexiones entre los diferentes agentes económicos y sociales. A este respecto, hay que señalar que los entrevistados aseveran que para el diseño y la ejecución de las iniciativas se generan relaciones muy diversas tanto en vertical como en horizontal. Por un lado, es frecuente ver iniciativas en las que diferentes agentes, que representan distintos intereses y partes de la sociedad civil, se unen para desarrollar alianzas y llevar a cabo proyectos que aumentan el bienestar general y satisfacen necesidades sociales. Por otro lado, existen iniciativas cuyo valor añadido reside en la actuación conjunta de la sociedad civil, el sector privado y/o las administraciones públicas.

Es precisamente ese contacto horizontal entre diferentes grupos de la sociedad civil, que canalizan su preocupación a partir de movimientos sociales o asociaciones, lo que genera que la segunda característica más importante en este bloque sea la acción social colectiva. Esta característica ha sido identificada como primordial para el desarrollo de la innovación social por Harris y Albury (2009), Oosterlynck et al. (2013) y Moulaert et al. (2013). A partir de la acción social colectiva los entrevistados señalan que se representan los intereses comunes de la sociedad y se produce una respuesta conjunta que permite la consecución de los objetivos por los que se inicia la acción. Así, la colaboración se erige como la tercera característica fundamental en el proceso de creación de los proyectos de innovación social. La colaboración, con independencia de quién lidere la acción, es el atributo que une a los diferentes agentes económicos y sociales a ayudarse y beneficiarse de las capacidades de las partes.

De igual forma también es importante la participación de los interesados. Esta se postula como la cuarta característica más significativa dentro de este bloque. Hace referencia a que las iniciativas sean abiertas y establezcan mecanismos para que todo aquel que crea que puede aportar participe. No obstante, aunque la participación es importante, está gana aún más relevancia cuando se da conjuntamente con una participación de proximidad. Es necesario que en los proyectos se refleje el conocimiento de aquellos que más conocen la problemática. Esta idea surge de la premisa que apuntan hasta doce de los entrevistados de que "quien más conoce un problema suelen ser aquellas personas que están en contacto permanente con él". La innovación social debe dar cabida a que estas personas puedan participar y codiseñar los proyectos, permitiendo así que sean parte de la solución de sus propias necesidades. Por ello, en los procesos socialmente innovadores a menudo se crean marcos para poder abordar los problemas con una perspectiva de proximidad (RodríguezGarcía y Mateos, 2015).

Finalmente, dentro de este bloque, debemos destacar que, en muchos de estos proyectos en los que coinciden gran parte de las características mencionadas, puede originarse que se formen redes que establecen y definen su propia estructura para facilitar su funcionamiento. La formación de redes es de gran relevancia ya que supone la consolidación de las relaciones que, mediante la acción social colectiva, la interconexión entre agentes o la colaboración se ha logrado. Esto va a permitir establecer un contacto permanente y una relación mucho más sólida para realizar nuevas actuaciones y resolver retos futuros.

\subsection{Características propias de proyecto}

Cuando señalamos las características del proyecto hacemos referencia a centrar la atención en la iniciativa que se presenta, sin tener en cuenta los efectos que produce ni los procesos que han generado aquellos que participan en ella. En este bloque hemos agrupado un total de siete atributos.

Entre todos los atributos el que más destaca es el marcado carácter territorial de las iniciativas. Las innovaciones sociales se encuadran bajo el marco del contexto territorial porque se producen y están condicionadas por él (Fontan et al., 2005; MacCallum, 2009). La territorialidad es característica de la innovacion social, ya que, al menos en la fase inicial, las iniciativas socialmente innovadoras suelen 
desarrollarse en un espacio limitado. En este sentido, los barrios y las ciudades suelen ser lugares idóneos para la puesta en marcha y el nacimiento de las acciones socialmente innovadoras encaminadas a afrontar y superar los problemas y retos sociales de sus residentes. Sin perjuicio de lo anterior, podemos afirmar que, aunque las iniciativas suelan originarse y desarrollarse en primera instancia en un espacio limitado, es importante que tengan potencial para su replicabilidad y la escalabilidad. Esta es la segunda característica con mayor peso dentro de este bloque. Las iniciativas socialmente innovadoras más significativas son aquellas que han podido crecer y ser llevadas a cabo en otros territorios.

En tercer lugar, otro atributo relevante sería que el proyecto plantee nuevas metodologías inclusivas para su desarrollo. En los proyectos de innovación social no se debe presentar únicamente mejores resultados, sino que además es muy significativo cómo se obtienen dichas mejoras (Caulier-Grice et al., 2012). Las iniciativas socialmente innovadoras deben caracterizarse por la inclusión de nuevas metodologías y formas de organización social que permitan mejorar tanto el proceso por el que se consiguen los objetivos, como estos mismos. No es posible lograr soluciones socialmente innovadoras a los retos y problemas existentes si se sigue realizando las mismas actuaciones ordinarias y tradicionales que venían desarrollándose hasta ahora. Por ello, es de suma importancia que, para el diseño y puesta en marcha de estos modelos alternativos novedosos, esté muy presente la creatividad. Ésta se encuentra muy determinada por las preocupaciones locales y globales del entorno, lo que condiciona las soluciones socialmente innovadoras. La creatividad como elemento característico de la innovación social es uno de los aspectos más ampliamente asumidos por la mayoría de los investigadores (André et al., 2009; Bresciani, 2010; Bresciani et al., 2013). Es la cuarta característica con mayor peso en este bloque.

La necesidad de generar procesos creativos que den lugar a iniciativas socialmente innovadoras y que incorporen nuevas metodologías inclusivas suelen caracterizarse también por presentar un proceso de aprendizaje continuado. Esta es el quinto atributo más significativo. Los modelos alternativos implican un mayor riesgo que suele ser paliado cuando se va incrementando la experiencia y el propio aprendizaje. Esto permite que los proyectos vayan mejorando a medida que el tiempo transcurre.

Por otro lado, la sexta característica identificada en este bloque como propia de los proyectos de innovación social es que suelen ser procesos de abajo arriba. Destacan por permitir que las ideas de las comunidades emerjan, dejando atrás los procesos de arriba abajo que no consideraban la posibilidad de integrar ideas y eran mucho más jerárquicos. Esta característica provoca, como subraya Navarro (2015), que se reintroduzca la inclusión social como eje prioritario para lograr un desarrollo local más sostenible.

El último atributo reconocido dentro de este bloque es el carácter cooperativo de los proyectos. Las iniciativas nacen desde el convencimiento de que aunar esfuerzos de forma colectiva genera mejores resultados que la búsqueda de soluciones de forma individual. Por lo tanto, la lógica socialmente innovadora deja atrás el espíritu individualista que ha predominado en las últimas décadas, postulando la cooperación como un elemento característico definitorio de la innovación social.

\subsection{Efectos característicos de la innovación social}

Estas características hacen referencia a los efectos generales que los proyectos de innovación social suelen tener. Este bloque engloba un total de cinco atributos.

La característica con mayor peso dentro de este bloque es que los proyectos repercutan en la sociedad civil. Los entrevistados afirman que las iniciativas socialmente innovadoras, independientemente del tipo de agentes económicos y sociales que las lleven a cabo, y al contrario de lo que ocurre con otro tipo de innovaciones, se caracterizan porque la sociedad civil es la beneficiaria directa de sus resultados (Moulaert $e t$ $a l ., 2004)$. La búsqueda de la transformación social es una característica común y deseable que cualquier iniciativa socialmente innovadora debería tener. Dicha transformación suele conllevar el aumento de calidad de vida de las personas ya que los procesos de innovación social suelen repercutir en diferentes ámbitos como la inserción laboral, la reducción de la desigualdad o la mayor inclusión social. El aumento de la calidad de vida es la segunda característica más relevante en este bloque y es uno de los elementos definitorios más reconocidos de las prácticas socialmente innovadoras (OCDE, 2011).

La tercera característica más significativa es los efectos en la transformación política. Una vez los proyectos son ejecutados en ocasiones originan cambios en las relaciones de poder (Lawson y Lorenz, 1999; Mulgan, 2006; Hubert, 2010; Moulaert et al., 2013). Aseveran los entrevistados que la innovación social posibilita a comunidades, en muchos casos relegadas a un segundo plano, a empoderarse y llegar incluso a generar economías comunitarias. Las innovaciones sociales otorgan a la sociedad civil un papel activo en la toma de decisiones pública y provocan transformaciones en la gobernanza.

Por otro lado, no hay que olvidar que otra de las características de este fenómeno es su transversalidad. Esta es la cuarta más relevante en este bloque. La innovación social está presente en los grandes retos que, a pesar de los avances tanto tecnológicos como económicos, aún no han sido resueltos. Ésta puede tener implicaciones en fenómenos como la migración, el despoblamiento, el envejecimiento, la desigualdad de género, la violencia, el cambio climático y el desempleo juvenil, entre otros (García-Flores y Palma, 2019). 
Por lo tanto, las iniciativas socialmente innovadoras permiten según su diseño y objetivos dar respuestas a retos sociales muy heterogéneos.

Por último, debemos destacar que las iniciativas socialmente innovadoras deben conllevar un aumento en la eficiencia y en la eficacia en la respuesta ante los retos y problemas sociales que abordan. Estas características son las últimas que se identifican dentro de este bloque. Para su análisis deben ser tenidos en cuenta los tradicionales aspectos económicos, pero también otros relacionados con la dimensión social. La mejora de la eficiencia y la eficacia en las iniciativas socialmente innovadoras ha sido señalada ampliamente en la literatura por autores como Caulier-Grice et al., (2012) Oosterlynck et al., (2013) o Cajaiba-Santana (2014).

\section{Las entidades del tercer sector como sujeto para el desarrollo de las innovaciones sociales. Análisis de un caso.}

Una vez identificadas y ponderadas las principales características que una iniciativa debe tener para ser reconocida como socialmente innovadora, creemos importante completar el estudio observando qué tipo de agentes económicos y sociales suelen liderarlas y diseñarlas. En este sentido, existen estudios como el realizado por Anheier (2014) que muestran que las entidades del tercer sector, como las asociaciones y las fundaciones, son las mejor posicionadas para coadyuvar a la irrupción de innovaciones sociales. Además, los entrevistados plantearon que las entidades del tercer sector son sujetos con facilidades, por sus características y capacidades, para el desarrollo de la innovación social, destacando especialmente las asociaciones. Las entidades del tercer sector fueron mencionadas como determinantes de la innovación social hasta en veintisiete ocasiones, siendo las asociaciones mencionadas en un total de dieciséis. Por ello, hemos realizado un análisis de un proyecto liderado por una entidad del tercer sector. Para la selección de nuestro caso hemos establecido los siguientes criterios:

- Que fuera una asociación.

- Que hubieran llevado a cabo iniciativas reconocidas por centro o institutos encargados de promover la innovación social como indicio de éxito o potencial innovador.

- Que nos permitiera conocer en profundidad las prácticas que llevaban a cabo a partir de la realización de entrevistas y el suministro de documentos.

Teniendo en cuenta estos criterios hemos elegido como sujeto para el caso al Grupo de Desarrollo Rural Valle del Guadalhorce ${ }^{15}$. En 2018 esta asociación fue reconocida como Nodo de Innovación Social en la provincia de Málaga. Este reconocimiento es otorgado por el Centro de Innovación Social La Noria ${ }^{16}$ y la obra social La Caixa, a través del Programa de apoyo a la implementación de proyectos de Innovación Social. Se recoge así fruto de las actuaciones que se han realizado desde la asociación en la última década y en las que ha tenido especial relevancia la mencionada Estrategia.

A continuación, pasamos a presentar el caso para posteriormente estudiar cómo encajan sus características principales con las propiedades definitorias identificadas previamente para cualquier práctica socialmente innovadora.

\section{Caso: Noria-Guadalhorce. Innovación Social en Áreas Rurales}

El Grupo de Desarrollo Rural Valle del Guadalhorce es una asociación sin ánimo de lucro integrada por habitantes de la localidad que, además de gestionar y ejecutar programas de ayuda al desarrollo rural, tienen como objetivo la dinamización económica, social y cultural, el crecimiento económico sostenible e integrador del territorio, la transparencia informativa y la cooperación. Para ello, esta entidad diseñó la Estrategia de Desarrollo Local del Valle del Guadalhorce 2016-2020, donde se proponía, siguiendo una lógica socialmente innovadora, un conjunto de medidas y acciones que permitiera alcanzar los objetivos anteriormente mencionados.

\section{¿Qué nuevo producto/servicio/modelo se propone?}

Esta asociación ha provocado un cambio social estructural a partir de la vertebración de un nuevo modelo productivo. Para este fin se han utilizado novedosas metodologías participativas, que han implicado a los agentes económicos y sociales de la comarca, permitiendo el diseño de una estrategia que recoge un conjunto

15 Puede ser consultado a través del siguiente enlace: https://www.valledelguadalhorce.com/ficheros/descargas/edl\%20gdr\%20valle\%20del\%20guadalhorce.pdf

16 Ver el dossier elaborado por La Noria Nuevos retos nuevas soluciones http://www.malaga.es/lanoria/7481/proyectos-2018. 
de medidas y acciones a desarrollar. Este conjunto de acciones ha logrado generar valor y reducir la dependencia económica del Valle del Guadalhorce de otros territorios a partir de la utilización de los recursos propios de la comarca. El proceso seguido para la elaboración de la Estrategia consta de tres fases ${ }^{17}$ :

En primer lugar, se realizó un diagnóstico DAFO (Debilidades, Amenazas, Fortalezas y Oportunidades) de la situación comarcal en la que se detectaron las necesidades y demandas de la población, así como las oportunidades y propuestas de actuación. Para ello, se crearon tanto mesas territoriales en cada uno de los municipios de la comarca, como mesas temáticas de los sectores claves, ofreciendo a los habitantes y agentes económicos y sociales la oportunidad de participar. Además, para la realización de la Estrategia, se llevaron a cabo diferentes grupos focales y entrevistas personales, facilitándose otras formas de participación a través de cuestionarios, redes sociales, web y blog.

La segunda fase consistió en la priorización y la validación de las necesidades y los objetivos a abordar en la Estrategia con los diferentes agentes económicos y sociales claves del territorio.

En la tercera y última fase de este proceso, se llevó a cabo el diseño y la validación del Plan de Acción propuesto por la Junta Directiva del Grupo de Desarrollo Rural Valle del Guadalhorce y aprobado por la Asamblea General.

Destaca de todo este proceso, por su relevancia y particularidad, que la metodología participativa para llevar a cabo el proceso participativo es la I.A.O (Investigación Acción Participativa) que está basada en la combinación de dos procesos: el conocimiento de la realidad y la implicación de la población cuya realidad se aborda. El uso de esta metodología ha permitido que la participación y la participación de proximidad, que recordamos son características propias y definitorias de la innovación social, estén presentes en esta iniciativa de forma muy significativa. Además, esta metodología, que combina la teoría y la praxis, posibilita el aprendizaje, la toma de conciencia crítica de la población sobre su realidad, su empoderamiento, el refuerzo y ampliación de sus redes sociales, su movilización colectiva y su acción transformadora. Así se ha permitido a los propios beneficiarios trabajar y colaborar para buscar respuestas a las necesidades prioritarias de la comarca: potenciando un desarrollo sostenible, igualitario y resiliente.

\section{¿Qué problema o necesidad social se satisface?}

La cercanía del Valle del Guadalhorce con la Costa del Sol, donde desde finales de la década de los 90 la construcción vivió un gran auge, hizo que muchas de las personas de la comarca emigraran del territorio para buscar trabajo a otras áreas cercanas. Esto provocó que la sociedad de la comarca del Valle del Guadalhorce fuera muy dependiente económicamente de otros territorios de la provincia. Sin embargo, con el fin de la burbuja de la construcción en 2008, aquellos que habían encontrado trabajo en este sector, vuelven a su comarca natal y es entonces cuando el alto desempleo se erige en un problema.

A esto se le suma la falta de cualificación y de estudios de la población desempleada, ya que la mayoría de ellos eran jóvenes que abandonaron sus estudios por la posibilidad de obtener empleos bien remunerados a una temprana edad. Por lo tanto, el alto desempleo, la despoblación rural y la alta dependencia económica de otros territorios, eran los principales retos a los que tenía que hacer frente esta comarca.

\section{¿Cuál es la mejora que se introduce?}

Desde que el mencionado problema se hace acuciante, el Grupo de Desarrollo Rural del Valle del Guadalhorce comienza a funcionar con una lógica socialmente innovadora, plasmándose muchas de las iniciativas que habían sido desarrolladas en la última década, en la Estrategia de Desarrollo Local del Valle del Guadalhorce 2016-2020. En ésta se recogen un conjunto de iniciativas que tienen como característica común estar diseñadas teniendo en consideración los recursos disponibles y las características rurales del entorno. Basándose en ello se propone un nuevo modelo productivo que tiene tres ejes principales: la agricultura y la ganadería, la industria agroalimentaria y el turismo sostenible.

En este sentido, desde la asociación se pretende que el sector agrario y sobre todo el ecológico sea el sector que cree más puestos de trabajo, desarrollando un sistema productivo fuerte y novedoso que permita una mayor soberanía y poder de decisión. Por otro lado, se busca contribuir a la consolidación de la industria agroalimentaria dado que en la sociedad existe una creciente tendencia al consumo de productos de cercanía y existen canales cortos de comercialización atractivos para los mercados locales. Por último, dado el potencial natural y paisajístico del Valle del Guadalhorce, se pretende fomentar el turismo activo y el turismo en la naturaleza, buscando crear una alternativa al turismo masivo de sol y playa.

17 El proceso puede ser consultado en la Estrategia en las páginas de la 18 a la 114. 
Muchas de estas líneas han tenido resultados muy positivos, muestra de ello es que se han creado asociaciones de agricultores para prestarse asistencia técnica mutua y se ha potenciado el cultivo de alimentos ecológicos. Así, es también una realidad la creación de una marca propia del Valle del Guadalhorce que permite identificar todos los productos y servicios de la comarca ${ }^{18}$, unificando bajo un mismo sello productos turísticos, deportivos y agroalimentarios. En cuanto al turismo destaca la difusión a nivel internacional de formatos de viajes alternativos (fam trips ${ }^{19}$, press trips ${ }^{20}$ ) y el crecimiento que se ha producido del número de establecimientos turísticos rurales de 2014 a 2018 que pasaron de 71 a $176^{21}$.

Por lo tanto, observamos como desde esta asociación se ha diseñado de forma novedosa, teniendo en cuenta la visión de los diferentes agentes económicos y sociales del territorio, un nuevo modelo productivo que aprovecha las características propias de la comarca, así como los recursos endógenos existentes, para generar nuevas oportunidades de negocio y reducir la alta dependencia económica que existía de otros territorios. Todo ello se ha realizado de una forma participativa, inclusiva y sostenible.

\section{¿Es realmente un proyecto socialmente innovador?}

Por último, antes de terminar nuestro estudio del caso, pasamos a analizar si están presente en el proyecto cada una de las características previamente identificadas. Esto nos va a permitir dirimir si la iniciativa es realmente socialmente innovadora. Para realizar este análisis hemos recogido en la tabla 3 cada una de las características y hemos observado si podía ser reconocida y cómo se manifestaba en el proyecto que acabamos de presentar.

Tabla. 3: Encaje de las características de una innovación social con la iniciativa Noria-Guadalhorce: Innovación Social en Áreas Rurales

\begin{tabular}{|c|c|}
\hline Característica & Idea del proyecto \\
\hline $\begin{array}{l}\text { 1. Interconexión } \\
\text { entre distintos } \\
\text { agentes }\end{array}$ & $\begin{array}{l}\text { El proyecto está liderado por una entidad del tercer sector, pero se cuenta con la } \\
\text { sociedad civil, la financiación de una entidad privada como La Caixa, el apoyo de la } \\
\text { Administración Pública a través de La Noria y la participación del sector privado } \\
\text { capitalista. }\end{array}$ \\
\hline $\begin{array}{l}\text { 2. Acción social } \\
\text { colectiva }\end{array}$ & $\begin{array}{l}\text { La unión de la sociedad para cambiar la realidad se ve reflejada en la formación de } \\
\text { la asociación, así como en la ejecución de sus acciones. }\end{array}$ \\
\hline 3. Colaboración & $\begin{array}{l}\text { Las relaciones entre los comerciantes de la zona, los productores agrícolas, la } \\
\text { sociedad civil y la propia asociación es fundamental para el éxito del modelo. }\end{array}$ \\
\hline 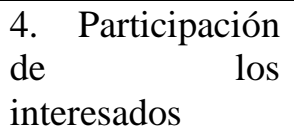 & $\begin{array}{l}\text { La solución de virar hacia un nuevo modelo económico se realizó gracias a las } \\
\text { aportaciones y la participación activa de los propios beneficiarios. }\end{array}$ \\
\hline 5. Proximidad & $\begin{array}{l}\text { La iniciativa cumple con el principio de proximidad. Quienes mejor conocían el } \\
\text { problema son quienes han propuesto la solución. Además, se ha realizado el proceso } \\
\text { teniendo en cuenta las características de la zona y utilizando los recursos de } \\
\text { cercanía: tierra muy dividida, fértil y de calidad. Esto ha permitido el cultivo de } \\
\text { productos únicos y de alto valor añadido. }\end{array}$ \\
\hline $\begin{array}{l}\text { 6. Elaboración de } \\
\text { redes }\end{array}$ & $\begin{array}{l}\text { En este caso, fruto de la tipología de negocios que se ha desarrollado y con el fin de } \\
\text { aprovechar sinergias, se han establecido redes para la venta de los productos con } \\
\text { diferentes comerciantes de la zona, así como con distintos mercados locales. }\end{array}$ \\
\hline $\begin{array}{l}7 . \quad \text { Elemento } \\
\text { territorial }\end{array}$ & $\begin{array}{l}\text { Esta innovación social viene determinada por el territorio. Su carácter local y su } \\
\text { entorno le suponen una ventaja competitiva para tener éxito. }\end{array}$ \\
\hline $\begin{array}{l}\text { 8. Replicabilidad } \\
\text { y escalabilidad }\end{array}$ & $\begin{array}{l}\text { Es un modelo cuya estructura es replicable y escalable. Éste ha sido diseñado a partir } \\
\text { del estudio de las necesidades de la población y estableciendo un plan para el } \\
\text { aprovechamiento de los recursos existentes en el enclave geográfico que se } \\
\text { encontraba. }\end{array}$ \\
\hline 9. Presencia de & La creatividad ha sido fundamental en todo el proceso ya que se ha logrado de una \\
\hline
\end{tabular}

19 Los fam trips son viajes que se ofrecen a operadores turísticos y agencias de viajes para que conozcan mejor un destino turístico con el fin de que puedan mejorar la comercialización de ese destino.

20 Los press trips se tratan de viajes organizados a profesionales del turismo: Periodistas de guías, revistas turísticas y medios de comunicación.

21 Datos obtenidos de http://www.prisma.global/Observatorio/SistemaInteligente (Fundación Madeca). 


\begin{tabular}{|c|c|}
\hline creatividad & $\begin{array}{l}\text { forma alternativa, imaginativa y novedosa, generar un nuevo modelo económico } \\
\text { sostenible. Se ha avanzado desde un modelo obsoleto que provocaba desempleo y } \\
\text { despoblación al diseño de otro mucho más eficiente. }\end{array}$ \\
\hline $\begin{array}{l}\text { 10. Proceso de } \\
\text { aprendizaje }\end{array}$ & $\begin{array}{l}\text { Se diseñó un modelo con gran potencial pero que demandaba un alto proceso de } \\
\text { aprendizaje, ya que en muchos casos conllevaba reconvertir a profesionales de la } \\
\text { construcción en profesionales agrarios. Por lo tanto, había que educar y formar a } \\
\text { aquellos potenciales trabajadores que en muchos casos no tenían nociones sobre el } \\
\text { mundo agrario. }\end{array}$ \\
\hline $\begin{array}{l}\text { 11. Metodologías } \\
\text { más inclusivas }\end{array}$ & $\begin{array}{l}\text { En la elaboración de este proyecto se ha tenido en consideración las experiencias y } \\
\text { opiniones de los propios beneficiarios. En todo momento, los arquitectos sociales } \\
\text { han tenido en cuenta los conocimientos de aquellos que mejor conocen el problema, } \\
\text { los afectados. }\end{array}$ \\
\hline 12. Cooperación & $\begin{array}{l}\text { No se idealiza la figura del emprendedor social como individuo generador de valor, } \\
\text { sino que se entiende que un conjunto de personas trabajando en el mundo agrario } \\
\text { pueden lograr una diversidad de productos de calidad y un modelo sostenible que } \\
\text { incrementa el bienestar general. }\end{array}$ \\
\hline $\begin{array}{l}\text { 13. Proceso de } \\
\text { abajo a arriba }\end{array}$ & $\begin{array}{l}\text { Es una solución co-diseñada y co-creada. Desde la base de la sociedad civil se } \\
\text { analiza la realidad y se propone una nueva práctica que conlleva un nuevo modelo } \\
\text { de negocio. }\end{array}$ \\
\hline $\begin{array}{l}\text { 14. Repercute en } \\
\text { la sociedad civil }\end{array}$ & $\begin{array}{l}\text { Los principales beneficiarios de los resultados de este proyecto son los habitantes del } \\
\text { Valle del Guadalhorce, que se han visto favorecidos por un sistema económico más } \\
\text { eficiente que genera empleo para la población local. }\end{array}$ \\
\hline $\begin{array}{l}\text { 15. Aumenta la } \\
\text { calidad de vida }\end{array}$ & $\begin{array}{l}\text { Gracias al proyecto que está siendo llevado a cabo, muchas personas lograron volver } \\
\text { a la comarca del Valle del Guadalhorce y encontrar un empleo. Además, se ha } \\
\text { dinamizado la economía local y se han aprovechado tierras que estaban en desuso. } \\
\text { En general, se ha logrado construir un modelo económico integrador que aumenta el } \\
\text { bienestar social. }\end{array}$ \\
\hline $\begin{array}{l}16 . \\
\text { Transformación } \\
\text { política }\end{array}$ & $\begin{array}{l}\text { El diseño del nuevo modelo económico ha sido desarrollado por la sociedad civil y } \\
\text { canalizado por el Grupo de Desarrollo Rural Valle del Guadalhorce. Se ha originado } \\
\text { un cambio de modelo en el que el diseño de la estructura económica no ha sido } \\
\text { dirigido desde ninguna administración, sino desde la propia sociedad civil. }\end{array}$ \\
\hline $\begin{array}{l}\text { 17.Fenómeno } \\
\text { transversal }\end{array}$ & $\begin{array}{l}\text { La iniciativa socialmente innovadora ha tenido impacto en diferentes ámbitos: ha } \\
\text { reducido el fenómeno del despoblamiento, ha frenado el envejecimiento poblacional, } \\
\text { ha generado un mayor consumo de productos locales y ha reducido el desempleo } \\
\text { juvenil. }\end{array}$ \\
\hline $\begin{array}{l}\text { 18.Respuestas } \\
\text { más eficientes y } \\
\text { eficaces }\end{array}$ & $\begin{array}{l}\text { La iniciativa ha logrado dar una respuesta a diversos problemas sociales de una } \\
\text { forma más eficaz y eficiente de la que la administración pública y el sector privado } \\
\text { capitalista había dado hasta ahora. }\end{array}$ \\
\hline
\end{tabular}

Fuente: Elaboración propia

A partir de la tabla 3, observamos que en el proyecto llevado a cabo por el Grupo de Desarrollo Rural del Valle del Guadalhorce están presentes todas las características previamente identificadas como definitorias de la innovación social. Esto evidencia que el proyecto desarrollado por la asociación es socialmente innovador. El encaje de las características propias de la innovación social con las del proyecto realizado no debe resultar casual, sino que guarda una estrecha relación con la propia naturaleza, la forma de organización y los objetivos de este tipo de entidades. Las entidades del sector, al contrario de lo que ocurre con la mayoría de las empresas del sector privado capitalista, tienen presentes como elemento central de sus actuaciones la dimensión social. Esto provoca que los principios que rigen el funcionamiento de este tipo de entidades les faciliten alinearse de manera natural con la construcción de iniciativas socialmente innovadora.

\section{Conclusiones}

El incremento de los retos globales, complejos y multidimensionales en las últimas décadas han posicionado a la innovación social como un fenómeno en auge y a las entidades del tercer sector como un sujeto con un rol cada vez más relevante. Este hecho ha causado que sean muchos los autores que han centrado sus estudios en estos campos. Nuestro trabajo ha evidenciado la coexistencia de diferentes enfoques y formas de 
entender la innovación social debido a las divergencias existentes acerca de cuáles son sus principales características definitorias, lo que ha dificultado la creación de un marco de referencia claro y común. También se ha mostrado que existe una amplia literatura que señala posibles implicaciones entre la innovación social y las entidades del tercer sector.

Nosotros entendemos que las entidades del tercer sector por los principios que encarnan se postulan como un sujeto clave para transformar el actual modelo socioeconómico. Éstas caracterizan sus actuaciones por el espíritu colectivo y la capacidad de asociación de los individuos para generar valor frente al espíritu individualista hegemónico y la figura del emprendedor que prevalecen en el modelo tradicional. Por ello, las entidades del tercer sector representan el cambio de paradigma que se pretende desarrollar a través de la innovación social. No obstante, y a pesar de la relación existente entre las entidades del tercer sector y las iniciativas socialmente innovadoras, no debe darse por hecho que toda iniciativa que desarrolle una entidad del tercer sector sea una innovación social. Cada una de ellas requieren un análisis individual que permita observar si realmente están alineadas con las características de la innovación social.

Por consiguiente, la identificación y ponderación de las características definitorias de la innovación social es sumamente importante para crear un nuevo marco que permita la valoración individualizada de cada una de las iniciativas. Por esta razón, nosotros hemos propuesto un nuevo marco compuesto por 18 características que hemos agrupado en 3 bloques (ver tabla 2): características de las relaciones de los agentes participantes en el proyecto, características propias del proyecto y efectos característicos de la innovación social.

El reconocimiento de tres grandes bloques de características implica que una iniciativa socialmente innovadora debería ser analizada en tres partes. Una primera en la que se centra la atención en las interacciones realizadas entre los agentes económicos y sociales que van a determinar el diseño del proyecto. Una segunda en la que se analiza el diseño del proyecto que ha sido realizado por los sujetos. Y, finalmente, una tercera donde se analizan los impactos potenciales que la ejecución del proyecto puede tener. Atendiendo a esta clasificación podemos afirmar que se confirma la hipótesis de que, para las iniciativas socialmente innovadoras, el proceso es igual o incluso más importante que el resultado final. La suma de los bloques que hacen referencia a la fase previa al diseño y a la propia del diseño, es decir, al primer y segundo bloque, suman 0.75 , mientras que el tercer bloque, que representaría la importancia de los resultados, tendría un peso de 0.25 .

Este nuevo marco genera un conocimiento de utilidad que está al servicio de aquellos interesados en el diseño y ejecución de programas que tengan como objetivo el apoyo económico y técnico de la innovación social. Este conocimiento puede facilitar la elaboración de unos criterios objetivos que contribuyan a determinar si una iniciativa es socialmente innovadora o no, e incluso a compararlas entre ellas.

Por lo tanto, basándonos en la identificación de esas características, y teniendo en cuenta la revisión de la literatura y el análisis del caso podemos señalar que, aunque puedan existir otro tipo de organizaciones que desarrollen prácticas socialmente innovadoras, las entidades del tercer sector, y más concretamente, las asociaciones, son sujetos con facilidades para llevar a cabo proyectos socialmente innovadores. Este reconocimiento muestra a aquellos organismos o entidades que quieran desarrollar prácticas socialmente innovadoras, que las entidades del tercer sector, por sus propias características y funcionamiento, tienen potencialidades para hacerlo con éxito.

Finalmente, nos gustaría señalar que este trabajo puede dar origen a futuras líneas de investigación relacionadas con la innovación social. Creemos especialmente interesante la posibilidad de realizar nuevos análisis para ver el encaje de las características identificadas con otros tipos de organizaciones como pueden ser las cooperativas. Asimismo, también entendemos que la profundización en el estudio de las relaciones entre las diferentes características señaladas puede contribuir a comprender mejor cómo diseñar procesos socialmente innovadores.

\section{Referencias bibliográfícas}

André, I., Henriques, E. B., y Malheiros, J. (2009) Inclusive Places, Arts and Socially Creative Milieux. En: MacCallum, D., Moulaert, F., Hillier, J. y Vicari, S. Social Innovation and Territorial Development. Farnham, Surrey, England: Ashgate Publishing Limited, pp.149-166.

Anheier, H.K. (2014) Nonprofit Organizations: An Introduction: Theory. Management, Policy. London: Routledge

Ariño, G. B., y Atxutegi, G. (2017) La innovación social en el País Vasco. De la teoría a la práctica. Revista española del tercer sector, $\mathrm{N}^{\circ} 36$, pp. 183-188.

Avelino, F. y Wittmayer, J. M. (2016) Shifting power relations in sustainability transitions: a multi-actor perspective. Journal of Environmental Policy y Planning, No 5, Vol. 18, pp. 628-649.

Bason, C. (2010) Leading Public Sector Innovation. Co creating for a better society. Bristol: Policy Press.

Blanco, I., Cruz, H. y Martinez, R. (2016) El papel de la innovación social frente a la crisis. Ciudad y Territorio. Estudios Territoriales, № 188 . Vol. 47, pp. 249-260. 
Borzaga, C. y Bodini, R. (2012) What to make of social innovation? Towards a framework for policy development. Euricse Working Paper, N. 036/12

Bresciani, S. (2010) Innovation within firms: a survey in the Piedmont area. International Journal of Quality and Innovation, $\mathrm{N}^{\circ}$ 2, Vol. 1, pp. 138-152.

Bresciani, S., y Ferraris, A. (2012) Imprese multinazionali. Innovazione e scelte localizzative. Romagna: Maggioli Editore.

Bureau of European Policy Advisors (BEPA) (2014) Social Innovation: A Decade of Changes, Luxemburg: Publications Office of the European Union.

Buckland, H. y Murillo, D. (2014) La innovación social en América Latina. Marco conceptual y agentes. Barcelona: Instituto de Innovación Social de ESADE y Fondo Multilateral de Inversiones.

Cajaiba-Santana, G. (2014) Social innovation: Moving the field forward. A conceptual framework. Technological Forecasting and Social Change. No 82, pp. 42-51, doi: 10.1016/j.techfore.2013.05.008.

Caulier-Grice, J., Davies, A., Patrick, R. y Norman, W. (2012) Defining social innovation. Brussels: A deliverable of the project: The theoretical, empirical and policy foundations for building social innovation in Europe (TEPSIE).

Comisión Europea (2013) Guía de la Innovación Social, Regional and Urban Policy, Bruselas.

Djellal, F. y Gallouj, F. (2012) Social innovation and service innovation. Challenge social innovation. En: Franz, H. W., Hochgerner, J. y Howaldt, J. Challenge social innovation: potentials for business, social entrepreneurship, welfare and civil society. Dortmund: Springer Science y Business Media, pp. 119-137, DOI: 10.1007/978-3-64232879-4_8.

Díaz-Foncea, M. y Marcuello, C. (2014) Las empresas sociales en España: concepto y características. Gizarte Ekonomiaren Euskal Aldizkaria-Revista Vasca de Economía Social, № 8, pp. 143-164.

Echeverría, J. y Merino, L. (2011) Cambio de paradigma en los estudios de innovación: el giro social de las políticas europeas de innovación. Arbor No 752 Vol. 187: pp. 1031-1043, doi: 10.3989/arbor.2011.752n6002.

Escalante, E. (2009) Métodos de análisis de las verbalizaciones: una contribución del análisis textual y conceptual mediante el uso de software. Encuentro, No 83, pp. 32-48, DOI: 10.5377/encuentro.v0i83.3598.

Fantova, F. (2015) Innovación social y tercer sector de acción social. En: Cabrero, G. Análisis prospectivo sobre los retos actuales y futuros del Tercer Sector de Acción Social. Madrid: Plataforma de Organizaciones No Gubernamentales de Acción Social, pp. 155-178.

Fazzi, L. (2014) Imprenditori sociali innovatori. Casi di studio nel terzo settore. Milano: Franco Angeli.

Fontan, J.M., Klein, J.L. y Lévesque, B. (2005) The fight for jobs and economic governance: the Montreal model. En: Booth, P. y Jouv, B. Metropolitan Democracies: Transformations of the State and Urban Policy in Canada, France and Great Britain, Aldershot: Burlington, pp. 133-146.

Fresno, J. M. y Rauchberger, C. (2015) Estudio tercer sector y provisión de servicios: prácticas europeas y lecciones para España. Madrid: Plena Inclusión.

Fundación Luis Vives (2012) Anuario del tercer sector de acción social en España. Madrid: Obra Social Caja Madrid.

García-Flores, V. y Palma, L. (2019) Innovación social: Factores claves para su desarrollo en los territorios. CIRIECEspaña, Revista de Economía Pública, Social y Cooperativa, № 97, pp. 245-278.

Godin, B. (2012) Social Innovation: Utopias of Innovation from c. 1830 to the Present. Project on the Intellectual History of Innovation Working Paper, $\mathrm{N}^{\mathrm{o}}$ 11, pp. 1-52.

Harris, M. y Albury, D. (2009) The innovation imperative. NESTA.

Hernández-Ascanio, J., Tirado-Valencia, P. y Ariza-Montes, A. (2016) El concepto de innovación social: ámbitos, definiciones y alcances teóricos. CIRIEC-España, Revista de Economía Pública, Social y Cooperativa, № 88, pp. 164-199, DOI: 10.7203/CIRIEC-E.88.8849.

Hirsch, P. M. y Levin, D. Z. (1999) Umbrella advocates versus validity police: A life-cycle model. Organization Science, $\mathrm{N}^{\mathrm{o}}$ 10, Vol. 2, pp. 199-212.

Hubert, A. (2010) Empowering people, driving change: Social innovation in the European Union. Luxembourg: Publications Office of the European Union.

Lawson, C. y Lorenz, E. (1999) Collective Learning, Tacit Knowledge and Regional Innovative Capacity, Regional Studies, No 33 , pp. 305-317.

López, J. A. y González, M. (2013). Encrucijadas sociales de la innovación. Isegoría, No 48, pp. 11-24, DOI: 10.3989/isegoria.2013.048.01.

López-Cózar, C., Priede Bergamini, T. y Del Arco Juan, J. (2015) La empresa social. Experiencias innovadoras a través del deporte. REVESCO. Revista de Estudios Cooperativos, Tercer Cuatrimestre, № 119, pp. 107-131. DOI: 10.5209/rev_REVE.2015.n119.49069.

MacCallum, D. (2009) Social innovation and territorial development. Wey Court East: Ashgate Publishing, Ltd. DOI: 10.4324/9781315609478.

McCracken, G. (1991) The long interview. $5^{\text {th }}$ ed. Newbury Park: Sage Publications.

Moulaert, F., Martinelli, F. y Swyngedouw. (2004) Social innovation and governance in local communities. Lille: SINGOCOM Final report to the EC (FP6).

Moulaert, F. y Nussbaumer, J. (2005) Defining social economy and its governance at the neighbourhood level: A methodological reflection, Urban Studies, No 11, Vol. 42, pp. 2071-2088.

Moulaert, F., Maccallum, D., Mehmood, A. y Hamdoch, A. (2013) The international handbook on social innovation: collective action, social learning and transdisciplinary research. Cheltenham: Edward Elgar Publishing. 
Moulaert, F. y MacCallum, D. (2019) Advanced introduction to social innovation. Cheltenham: Edward Elgar Publishing.

Mulgan, G. (2006) The process of social innovation. Innovations: technology, governance, globalization, $\mathrm{N}^{\mathrm{o}} 2$, Vol. 1 , pp. 145-162, doi: 10.1162/itgg.2006.1.2.145.

Murray, R., Caulier-Grice, J., y Mulgan, G. (2010) The open book of social innovation. London: National endowment for science, technology and the art (NESTA).

Navarro, C. (2015) Innovación social y gobernanza urbana. En: Subirats, J. y García Bernardos, A. Innovación social y políticas urbanas en España: experiencias significativas en las grandes ciudades. Barcelona: ICARIA, pp.43-58.

Noguero, F. (2002) El análisis de contenido como método de investigación. Revista de Educación, № 4, pp. 167-179, DOI: $10.23878 /$ empr.v12i45.129.

OCDE (2011) Fostering Innovation to Address Social Challenges. Workshop proceedings. OCDE Innovation Strategy, DOI: 10.1016/j.techfore.2015.08.011.

Oosterlynck, S., Kazepov, Y., Novy, A., Cools, P., Barberis, E., Wukovitsch, F. y Leubolt, B. (2013) The butterfly and the elephant: local social innovation, the welfare state and new poverty dynamics. ImPRovE Methodological Paper, No2, Vol. 13, pp. 1-45.

Palma, L., García-Flores, V. y Fernández, I. (2017) La Agencia de Defensa de la Competencia de Andalucía como agente de innovación social en el marco de la Estrategia Europea de Especialización Inteligente. Comunicación presentada en el XVIII Congreso de Economía Regional celebrado en Sevilla, los días 15 ,16 y 17 de noviembre de 2017.

Pérez-López, R., Moráles-Sanchez, M., Anguera, T. y Hernandez-Mendo, A. (2015) Evaluación de la calidad total en servicios municipales deportivos orientados a la población infantil: Aportaciones desde el análisis cualitativo con Atlas.ti. Cuadernos de Psicología del Deporte, $\mathrm{N}^{\mathrm{o}}$ 1, Vol. 15, pp. 143-150, DOI: 10.4321/s157884232015000100014.

Phills, J. A., Deiglmeier, K., y Miller, D. T. (2008) Rediscovering social innovation. Stanford Social Innovation Review, $\mathrm{N}^{\mathrm{0}}$ 4, Vol. 6, pp. 34-43.

Prados, J. A. (2007) Críticas y apoyos hacia la responsabilidad social de la empresa: una aproximación etnográfica desde la vivencia del trabajador y una prop uesta metodológica cualitativa. Universitas psychologica, $\mathrm{N}^{\mathrm{o}} 1$, Vol. 6 , pp. 59-68.

PwC (2018) Radiografía del Tercer Sector Social en España: retos y oportunidades en un entorno cambiante. Madrid.

Rincón, C. A. (2013) La economía social desde tres perspectivas: tercer sector, organizaciones no gubernamentales y entidades sin ánimo de lucro. Revista Tendencias y Retos, № 1, Vol. 18, pp. 143-158.

Rodríguez-García, M. y Mateos, C. (2015) Decrecimiento, comunidades locales y recuperación de solidaridades vecinales. El caso de la moneda social "puma". En: Subirats, J. y García Bernardos, A. Innovación social y políticas urbanas en España: experiencias significativas en las grandes ciudades. Barcelona: ICARIA, pp. 145-152.

Roitter, M. (2004) El tercer sector como representación topográfica de sociedad civil. Políticas de ciudadanía y sociedad civil en tiempos de globalización. Caracas: FACES, Universidad Central de Venezuela, pp. 17-32.

Sajardo-Moreno, A. (2016) Nuevos instrumentos de financiación para el sector no lucrativo: el reto del crowdfunding social. Cooperativismo y Desarrollo, $\mathrm{N}^{\circ} 24$, Vol 108, pp. 39-53.

Sajardo Moreno, A. y Pérez Sempere, S. (2019) Análisis de las plataformas de crowdfunding social en el estado español: un estudio de casos. REVESCO. Revista de Estudios Cooperativos, Primer Cuatrimestre, $\mathrm{N}^{\circ} 130$, pp. 149175.DOI: 10.5209/REVE.61938.

Salamon, L. M., y Anheier, H. K. (1994) Caring sector or caring society?: Discovering the nonprofit sector crossnationally. Maryland: The Johns Hopkins University Institute for Policy Studies.

Salamon, L. M., y Anheier, H. K. (1996) Defining the nonprofit sector: the United States. Baltimore: Johns Hopkins University Institute for Policy Studies.

Salom-Carrasco, J., Pitarch-Garrido, M. y Sales-Ten, A. (2017) Innovación social: estrategias urbanas en un contexto de cambio. El caso de la ciudad de Valencia. CIRIEC-España, Revista de Economía Pública, Social y Cooperativa, $\mathrm{N}^{\circ}$ 91, pp. 31-58, DOI: 10.7203/CIRIEC-E.91.10451.

Schumpeter, J. (1942) Capitalismo, socialismo y democracia. Orbis.

Social Platform (2013) Social Platform's position on social innovation. Adopted by the Steering Group on December 3 , 2013.

Subirats, J. (2015) Políticas urbanas e innovación social. Entre la coproducción y la nueva institucionalidad. Criterios de significatividad. En: Subirats, J. y García Bernardos, A. Innovación social y políticas urbanas en España: experiencias significativas en las grandes ciudades. Barcelona: ICARIA, pp. 95-112.

Torres Prados, I. (2010). Identidad institucional de las organizaciones del Tercer Sector. Revista Internacional de Organizaciones, $\mathrm{N}^{\mathrm{0}}$ 5, pp. 7-29.

World Economic Forum y Schwab Foundation for Social Entrepreneurship (2016) Social Innovation: A Guide to Achieving Corporate and Societal Value. Switzerland: World Economic Forum.

Zubero, I., 2015. Innovación social: una propuesta para pensar las prácticas sociales en clave de transformación En: Subirats, J. y García Bernardos, A. Innovación social y políticas urbanas en España: experiencias significativas en las grandes ciudades. Barcelona: ICARIA, pp.13-42. 
Anexo 1. Guión utilizado para la realización de las entrevistas semiestructuradas a los diferentes agentes económicos y sociales.

\section{Parte I. Preguntas genéricas sobre innovación social}

1. Desde su punto de vista, ¿qué es para usted la innovación social?

2. ¿Cuáles cree que son las principales características y/o propiedades que debe tener una iniciativa o actividad para considerarla como una innovación social?

3. ¿Cree que se está sobreutilizando el concepto de innovación social? ¿Teme que pierda su valor?

4. ¿Qué motivos cree que llevan a los agentes a realizar prácticas socialmente innovadoras? En su caso o el de su asociación/empresa/sector representado, ¿cuál fue su motivación principal?

5. ¿Qué papel cree que juegan en la innovación social los centros de apoyo a la innovación social? ¿Y los académicos? ¿Señalaría algún otro agente que fuera relevante para el fomento y desarrollo de las innovaciones sociales? ¿Qué tipo de apoyo ha recibido su asociación /empresa?

6. ¿Cuál cree que es el perfil de los agentes socialmente innovadores? ¿Qué tipo de organizaciones, empresas (centros tecnológicos, empresariales, cooperativas...), organismos públicos cree que pueden llevar a cabo actividades socialmente innovadoras?

7. ¿Qué etapas cree que suele pasar una iniciativa socialmente innovadora desde que nace hasta que se consolida? ¿Cuál es la fase más crítica?

\section{Parte II: Identificación de variables}

8. ¿En qué tipo de regiones cree que se desarrollan las innovaciones sociales?

9. ¿Cree que en aquellas regiones donde existen más problemas, surgen más innovaciones sociales?

10. ¿Qué factores facilitaron el lanzamiento de su iniciativa socialmente innovadora?

11. ¿Qué factores supusieron una barrera o dificultaron dicho proceso?

12. Si tuviese que elegir tres grandes pilares que son esenciales para el desarrollo y fomento de las innovaciones sociales, ¿cuáles serían?

13. ¿Cómo cree que pueden ser medidos dichos factores?

14. ¿Quién cree que puede promover que esos factores que usted menciona puedan ser incentivados?

15. ¿Qué papel considera que tiene la creatividad sobre la innovación social? ¿Y el arte y la cultura?

\section{Parte III: Las potencialidades de la innovación social}

16. ¿Cuáles cree que son los principales beneficios de llevar a cabo actividades socialmente innovadoras para la sociedad?

17. ¿En qué campos cree que puede ser especialmente útil o relevante el desarrollo de innovaciones sociales? ¿Qué tipo de problemas cree que puede ayudar a resolver?

18. ¿Cree que puede ser afirmado que aquellas regiones donde existen menos problemas es porque hay iniciativas socialmente innovadoras? ¿O cree que la poca incidencia de determinados problemas en una región precisamente desincentiva la innovación social?

19. ¿Qué papel cree que tiene la innovación social en la mejora y la modernización del sector público?

20. ¿Qué implicaciones positivas cree que su iniciativa genera en la sociedad?

21. ¿Cuál es el objetivo de su iniciativa/centro/grupo de investigación a medio plazo? 
Anexo 2: Entidades a las que pertenecían las personas que han sido entrevistadas para la realización del trabajo

\begin{tabular}{|c|c|}
\hline $\begin{array}{l}\text { Entidad a la que pertenecían los responsables de } \\
\text { centros o empresas que promueven la innovación } \\
\text { social }\end{array}$ & Webs \\
\hline Red Guadalinfo. & $\begin{array}{l}\text { https://blog.guadalinfo.es/etiqueta/innovacion- } \\
\text { social/ }\end{array}$ \\
\hline Centro de Innovación Social de la provincia de Málaga. & http://www.malaga.es/lanoria/ \\
\hline $\begin{array}{l}\text { Laboratorio de innovación social y digital "Citilab } \\
\text { Cornellà" }\end{array}$ & https://www.citilab.eu/ \\
\hline "Espacio Res" & https://espaciores.org/es/ \\
\hline $\begin{array}{llllll}\text { Área de Innovación y } & \text { Economía Social en el } \\
\text { Ayuntamiento de Sevilla } & & & & \\
\end{array}$ & $\begin{array}{l}\text { https://www.sevilla.org/servicios/ } \\
\text { empleo/innovacion-social }\end{array}$ \\
\hline Innobasque (Agencia Vasca de Innovación) & https://www.innobasque.eus/ \\
\hline Ashoka & https://www.ashoka.org/es \\
\hline UpSocial & https://upsocial.org/es \\
\hline $\begin{array}{l}\text { Área de Servicios a la Ciudadanía de la Diputación } \\
\text { Provincial de Málaga }\end{array}$ & http://www.malaga.es/ \\
\hline $\begin{array}{l}\text { Entidad a la que pertenecían los académicos y } \\
\text { personas que han publicado trabajos de impacto } \\
\text { sobre innovación social Posición }\end{array}$ & Webs \\
\hline Innove & http://www.innove.com.co/ \\
\hline $\begin{array}{l}\text { Instituto de Gobierno y Políticas Públicas de la } \\
\text { Universidad Autónoma de Barcelona. }\end{array}$ & http://uab.academia.edu/ \\
\hline $\begin{array}{l}\text { Departamento de Didáctica y Organización Escolar en } \\
\text { la Universidad Deusto. }\end{array}$ & https://www.deusto.es/cs/ \\
\hline $\begin{array}{l}\text { Investigadora y coautora del trabajo "Panorama actual } \\
\text { de la Innovación Social en Colombia". Cofundadora de } \\
\text { la iniciativa "Innove" en Colombia, para promover la } \\
\text { innovación social. }\end{array}$ & http://labuenaempresa.com/ \\
\hline $\begin{array}{l}\text { Departamento de Economía Aplicada de la Universidad } \\
\text { de Vigo. }\end{array}$ & https://www.uvigo.gal/ \\
\hline $\begin{array}{l}\text { Departamento de Economía Financiera y Contabilidad } \\
\text { en la Universidad Loyola. }\end{array}$ & https://uloyola.academia.edu/ \\
\hline $\begin{array}{l}\text { Entidad a la que pertenecían los directores y } \\
\text { encargados de proyectos de innovación social de } \\
\text { impacto. }\end{array}$ & Webs \\
\hline Grupo de Desarrollo Rural del Valle del Guadalhorce & http://www.valledelguadalhorce.com/ \\
\hline $\begin{array}{l}\text { Federación Andaluza de Empresas Cooperativas de } \\
\text { Trabajo (FAECTA) }\end{array}$ & https://www.faecta.coop/index.php?id=inicio \\
\hline Asociación Arrabal & $\begin{array}{l}\text { https://asociacionarrabal.org/portfolio/crafteando- } \\
\text { mi-pueblo }\end{array}$ \\
\hline Mouse4all & https://mouse4all.com/es/ \\
\hline Asociación Asprodisis & http://www.asprodisis.org/ \\
\hline Asociación Perros y Letras en España -READ- & https://www.perrosyletras.com/ \\
\hline La Hidra Cooperativa. & http://lahidra.net/ \\
\hline Fundación "Pau Costa". & http://www.paucostafoundation.org/ \\
\hline Asociación Ecoherencia. & https://www.ecoherencia.es/ \\
\hline
\end{tabular}

